\title{
Pre-mating, Mating and Ovipositional duration of Gamma Irratated Uzi Fly, a Parasitoid of Mulberry Silkworm Bombyx mori L.
}

\author{
G. Ashwini* and Fatima Sadatulla \\ Department of Sericulture, University of Agricultural Sciences, \\ GKVK, Bengaluru-560065, India \\ *Corresponding author
}

\begin{abstract}
A B S T R A C T
Keywords

Uzi fly, Silk worm, Gamma radiation

Article Info

Accepted:

25 February 2019

Available Online:

10 March 2019

The gamma radiation was given to 4 day and 8 day old pupae of uzi flies at two effective doses of 1.5 and $2 \mathrm{kr}$ and the observations were recorded for two generations and the study was carried out in the department of Sericulture, UAS, GKVK, Bengaluru. The pre-mating duration was significantly different between 1.5 and $2 \mathrm{kr}$ when 4 day old pupae and 8 day old pupae were irradiated, the mating duration was not significantly different between 1.5 and $2 \mathrm{kr}$ when 4 day old pupae and 8 day old pupae were irradiated. The ovipositional duration showed a significant difference between 1.5 and $2 \mathrm{kr}$ when 4 day old pupae were irradiated and no significant difference between 1.5 and $2 \mathrm{kr}$ when 8 day old pupae were irradiated in the first generation. Whereas in the second generation, the pre-mating duration, mating duration and ovipositional duration did not vary significantly between 1.5 and $2 \mathrm{kr}$ when 4 day old pupae and 8 day old pupae were irradiated.
\end{abstract}

\section{Introduction}

Uzi flies belong to the family Tachinidae of the order Diptera, are of the most important among the insect pests, which attack the silkworm species and causes extensive loss to the sericulture industry. The application of synthetic organic pesticides has tremendous impact on minimizing pest population but their overuse and frequent misuse and high sensitivity towards the silkworms, has forced the entomologists to search for alternatives to chemical control, which is safe to silkworm and environment. The sterile insect technique (SIT) is an autocidal insect control method whereby numbers of sterile insects are released into the wild. The sterile males compete with wild males to mate with the females. Females that mate with a sterile male produce no offspring, thus reducing the next generation's population. Sterile insects are not self-replicating and, therefore, cannot become established in the environment.

\section{Materials and Methods}

The uzi fly maggots were collected from the cocoon market, Vijayapura, in plastic boxes with perforated lid and the uzi maggots were placed on sand bed in dark condition for pupation. After emergence, all the adult uzi flies were provided with 10 per cent glucose 
solution in cotton wads kept in the petri plates as food. The cotton wads dipped in 10 per cent glucose solution were replaced every day till the death of the uzi flies. Separation of 4 and 8 day old male uzi pupae (sex separation was done based on the size and weight of pupae).The separated male uzi pupae were irradiated using a ${ }^{60} \mathrm{C}$ source (gamma radiation), model BI 2000,the facility available at National Centre for Biological Sciences (NCBS), GKVK Campus, Bengaluru. The gamma radiation was given at two effective doses of 1.5 and $2 \mathrm{kr}$ to the male pupae. During the irradiation process, the pupae were kept in plastic containers with lid. The electronic dose measuring unit attached to the machine recorded the dosage delivered to each batch, which was noted down. Three replications were maintained for each dosage, with 50 pupae constituting each replication, along with control for two different aged pupae of 4 and 8 day old. The irradiated batches of uzi pupae were confined in separate rearing cages and utilized to record the observations.

The data obtained was analyzed using Factorial CBD. There are two treatments with two factors i.e., factor 1 is age (4 and 8 day old irradiated pupae) and factor 2 is radiation (1.5 kr and $2 \mathrm{kr}$ ).

\section{Results and Discussion}

\section{Pre-mating duration of male uzi flies emerged from irradiated pupae}

In the first generation, the pre-mating duration was significantly different between 1.5 and 2 $\mathrm{kr}$ (50.70 $\mathrm{min}$ and $64.97 \mathrm{~min}$ ) respectively when 4 day old pupae were irradiated and were also significantly different between 1.5 and $2 \mathrm{kr} \quad(50.70 \mathrm{~min}$ and $64.97 \mathrm{~min})$ respectively when 8 day old pupae were irradiated. Whereas in the subsequent generation the pre-mating duration did not vary significantly between 1.5 and $2 \mathrm{kr}(62.23$ min and $52.43 \mathrm{~min}$ ) respectively when 4 day old pupae were irradiated and there was no significant difference between 1.5 and $2 \mathrm{kr}$ (52.80 $\mathrm{min}$ and $63.53 \mathrm{~min}$ ) respectively when 8 day old pupae were irradiated. There was a significant difference between the control and treated batches (Table 1 and Fig. 1). The Statistical analysis revealed that dose of radiation was significant and the age of pupae was non-significant in both the generations. Similar observations were recorded by Vasudha (2014) where the pre-mating duration was $51.36 \mathrm{~min}$ and $51.33 \mathrm{~min}$ when 4 and 8 day old pupae were irradiated at 1.5 $\mathrm{kr}$ respectively and $50.23 \mathrm{~min}$ and $51.26 \mathrm{~min}$ when 4 and 8 day old pupae were irradiated at $2 \mathrm{kr}$ respectively. Frank et al., (1984) recorded the mating competitiveness of irradiated males mated with normal females of day 1, 8 and 15 days adults were irradiated at 0-20 rad. As irradiated males aged, their progeny's hatching percentage declined significantly. Percentage of hatching equaled $46.9 \%$ for eggs sired on day 1 , and $36.4 \%$ on day 15 , a $22 \%$ loss was observed.

\section{Mating duration of male uzi flies emerged from irradiated pupae}

In the first generation, the mating duration was not significantly different between 1.5 and $2 \mathrm{kr}(1.61 \mathrm{~h}$ and $1.43 \mathrm{~h})$ respectively when 4 day old pupae were irradiated and no significant difference between 1.5 and $2 \mathrm{kr}$ $(1.38 \mathrm{~h}$ and $1.56 \mathrm{~h})$ respectively when 8 day old pupae were irradiated. Whereas in the second generation, the mating duration showed no significant difference between the treatment means of 4 and 8 old irradiated pupae (4.18 $\mathrm{h}$ and $3.10 \mathrm{~h})$ respectively and no significant difference between the treatment means at 1.5 and $2 \mathrm{kr}(3.16 \mathrm{~h}$ and $3.49 \mathrm{~h})$ respectively. There was no variation between the treated batches and control in both the generations (Table 2 and Fig. 2). The 
Statistical analysis revealed that both dose of radiation and age of pupae are non-significant in the first generation whereas in the second generation, dose of radiation was significant and age of pupae was non-significant. Similar findings have been recorded by Frank et al., (1984) where the young male moths of Galleria melonella were exposed to either 0 or $20 \mathrm{rad}$ of ionizing radiation. Treated males competed with normal males for virgin females at 1,8 and 15 days of age. Mating competitiveness decreased as irradiated males aged. According to John and Brower (1976) the mating ability of males with single females was not significantly affected by irradiation doses in the Indian meal moth, Ploida interpunctella which is contradictory with the present results.

Table.1 Pre-mating duration of male uzi flies emerged from irradiated pupae (first and second generations)

\begin{tabular}{|c|c|c|c|c|c|c|}
\hline \multirow{2}{*}{$\begin{array}{c}\text { Radiation } \\
(\mathbf{k r})\end{array}$} & \multicolumn{2}{|c|}{$\begin{array}{c}\text { Pre-mating } \\
\text { duration (min.) }\end{array}$} & \multirow{2}{*}{ Mean } & \multicolumn{2}{|c|}{$\begin{array}{c}\text { Pre-mating } \\
\text { duration(min.) }\end{array}$} & \multirow{2}{*}{ Mean } \\
\cline { 2 - 3 } & \multicolumn{2}{|c|}{$1^{\text {st }}$ generation } & & \multicolumn{2}{|c|}{$2^{\text {nd }}$ generation } & \\
\cline { 2 - 3 } & $4^{\text {th }}$ day & $8^{\text {th }}$ day & & $4^{\text {th }}$ day & $8^{\text {th }}$ day & \\
\hline \multirow{2}{*}{$\mathbf{1 . 5}$} & 63.60 & 50.70 & $57.15^{\text {a }}$ & 62.23 & 52.80 & $57.51^{\text {a }}$ \\
\hline $\mathbf{2 . 0}$ & 48.70 & 64.97 & $56.83^{\text {a }}$ & 52.43 & 63.53 & $57.98^{\mathrm{a}}$ \\
\hline Control & 38.57 & 37.73 & $38.15^{\text {b }}$ & 41.53 & 43.07 & $42.30^{\text {b }}$ \\
\hline Mean & 50.28 & 51.13 & & 52.06 & 53.13 & \\
\hline
\end{tabular}

\begin{tabular}{|c|c|c|c|}
\hline $\mathbf{1}$ & Radiation & Age of pupae & $\begin{array}{c}\text { Radiation } \times \text { Age } \\
\text { of pupae }\end{array}$ \\
\hline F-test & $*$ & NS & $*$ \\
\hline SEm \pm & 3.43 & 2.80 & 4.86 \\
\hline CD at 5\% level & 10.58 & 8.64 & 14.97 \\
\hline $\mathbf{2}^{\text {nd }}$ generation & \multicolumn{3}{|l|}{} \\
\hline F-test & $*$ & NS & $*$ \\
\hline SEm \pm & 2.30 & 1.88 & 3.26 \\
\hline CD at 5\% level & 7.26 & 5.93 & 10.27 \\
\hline
\end{tabular}

Note:

1. Means followed by the same alphabet are not significantly different.

2. *Significant at $5 \%$ level.

3. NS: Non-significant. 
Table.2 Mating duration of male uzi flies emerged from irradiated pupae (first and second generations)

\begin{tabular}{|c|c|c|c|c|c|c|}
\hline \multirow{2}{*}{$\begin{array}{c}\text { Radiation } \\
(\mathbf{k r})\end{array}$} & \multicolumn{2}{|c|}{ Mating duration (h) } & \multirow{2}{*}{ Mean } & \multicolumn{2}{|c|}{ Mating duration (h) } & \multirow{2}{*}{ Mean } \\
\cline { 2 - 3 } & \multicolumn{2}{|c|}{$1^{\text {st }}$ generation } & & \multicolumn{2}{|c|}{$2^{\text {nd }}$ generation } & \\
\cline { 2 - 3 } & $4^{\text {th }}$ day & $8^{\text {th }}$ day & & $4^{\text {th }}$ day & $8^{\text {th }}$ day & \\
\hline $\mathbf{1 . 5}$ & 1.61 & 1.38 & 1.49 & 4.18 & 3.16 & $3.67^{\mathrm{b}}$ \\
\hline $\mathbf{2 . 0}$ & 1.43 & 1.56 & 1.49 & 3.10 & 3.49 & $3.29^{\mathrm{b}}$ \\
\hline Control & 1.50 & 1.53 & 1.51 & 4.27 & 4.59 & $4.43^{\mathrm{a}}$ \\
\hline Mean & 1.51 & 1.48 & & 3.84 & 3.74 & \\
\hline
\end{tabular}

\begin{tabular}{|c|c|c|c|}
\hline & Radiation & Age of pupae & $\begin{array}{c}\text { Radiation } \times \text { Age of } \\
\text { pupae }\end{array}$ \\
\hline $\mathbf{1}^{\text {st }}$ generation & NS & NS & $*$ \\
\hline SEm \pm & 0.032 & 0.02 & 0.05 \\
\hline CD at 5\% level & 0.11 & 0.08 & 0.16 \\
\hline $\mathbf{2}^{\text {nd }}$ generation & & & NS \\
\hline F-test & $*$ & NS & 0.29 \\
\hline SEm \pm & 0.20 & 0.16 & 0.88 \\
\hline CD at 5\% level & 0.62 & 0.50 & \\
\hline
\end{tabular}

Note:

1. Means followed by the same alphabet are not significantly different.

2. *Significant at $5 \%$ level.

3. NS: Non-significant. 
Table.3 Ovipositional duration of normal female uzi flies mated with male uzi flies emerged from irradiated pupae (first and second generations)

\begin{tabular}{|c|c|c|c|c|c|c|}
\hline \multirow[t]{3}{*}{$\begin{array}{c}\text { Radiation } \\
\text { (kr) }\end{array}$} & \multirow{2}{*}{\multicolumn{2}{|c|}{$\begin{array}{c}\begin{array}{c}\text { Ovipositional } \\
\text { duration (days) }\end{array} \\
1^{\mathrm{st}} \text { generation }\end{array}$}} & \multirow[t]{3}{*}{ Mean } & \multirow{2}{*}{\multicolumn{2}{|c|}{$\begin{array}{c}\begin{array}{c}\text { Ovipositional } \\
\text { duration (days) }\end{array} \\
2^{\text {nd }} \text { generation }\end{array}$}} & \multirow[t]{3}{*}{ Mean } \\
\hline & & & & & & \\
\hline & $4^{\text {th }}$ day & $8^{\text {th }}$ day & & $4^{\text {th }}$ day & $8^{\text {th }}$ day & \\
\hline 1.5 & 3.94 & 3.16 & $3.55^{b}$ & 2.43 & 2.89 & $2.51^{b}$ \\
\hline 2.0 & 3.10 & 3.49 & $3.29^{b}$ & 2.74 & 2.68 & $2.71^{b}$ \\
\hline Control & 4.27 & 4.59 & $4.43^{\mathrm{a}}$ & 4.30 & 4.49 & $4.39^{\mathrm{a}}$ \\
\hline Mean & 3.77 & 3.74 & & 3.05 & 3.35 & \\
\hline
\end{tabular}

\begin{tabular}{|c|c|c|c|}
\hline \multirow{yyn}{*}{$\mathbf{1}^{\text {st }}$ generation } & Radiation & Age of pupae & $\begin{array}{c}\text { Radiation } \times \text { Age } \\
\text { of pupae }\end{array}$ \\
\cline { 1 - 4 } F-test & $*$ & NS & $*$ \\
\hline SEm \pm & 0.14 & 0.11 & 0.21 \\
\hline CD at 5\% level & 0.46 & 0.37 & 0.65 \\
\hline $\mathbf{2}^{\text {nd }}$ generation & & & \\
\hline F-test & $*$ & $*$ & NS \\
\hline SEm \pm & 0.14 & 0.11 & 0.20 \\
\hline CD at 5\% level & 0.43 & 0.35 & 0.61 \\
\hline
\end{tabular}

\section{Note:}

1. Means followed by the same alphabet are not significantly different.

2. *Significant at $5 \%$ level.

3. NS: Non-significant. 
Fig.1 Pre-mating duration (min.) of male uzi flies emerged from irradiated pupae (first and second generations)

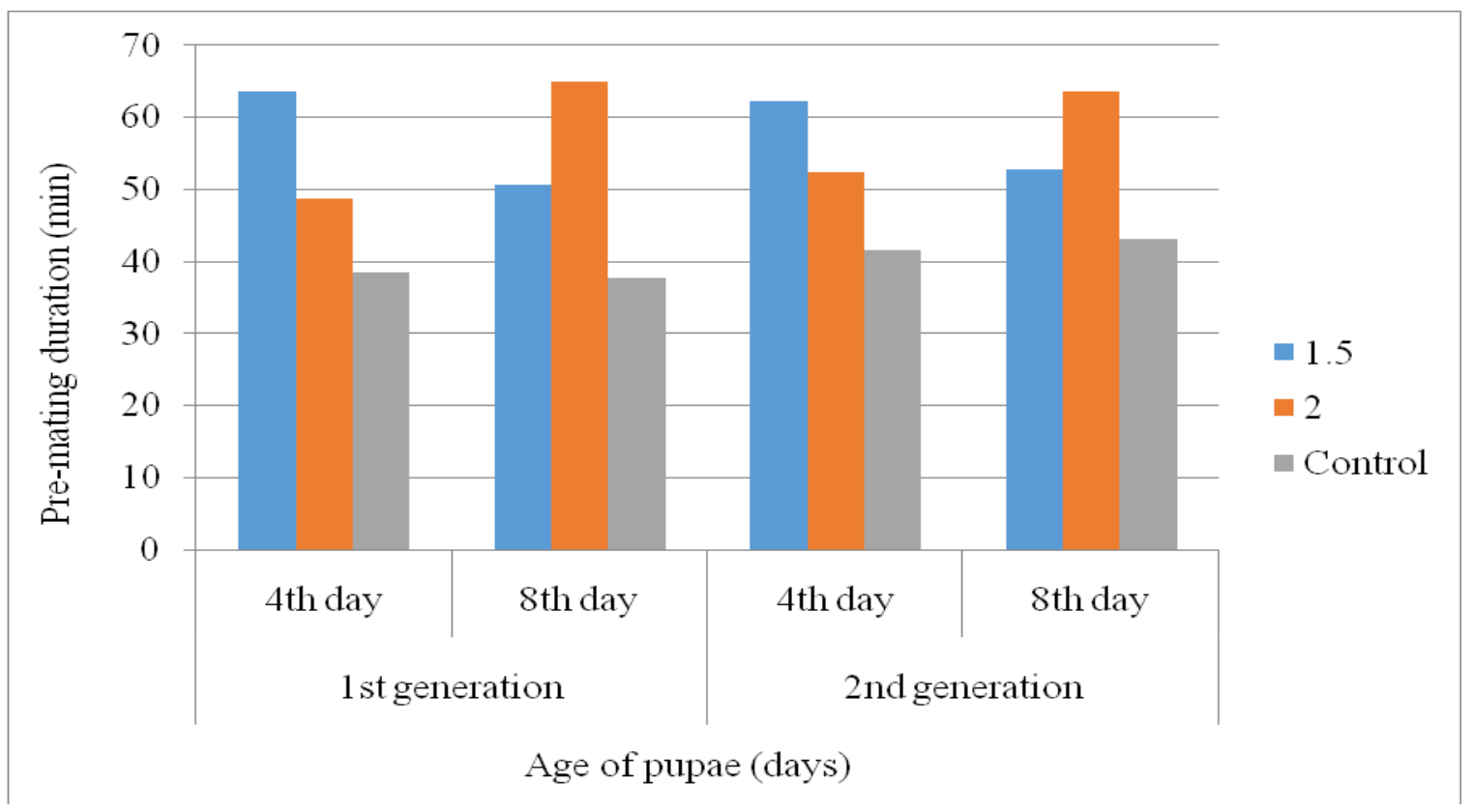

Fig.2 Mating duration (h) of male uzi flies emerged from irradiated pupae (first and second generations)

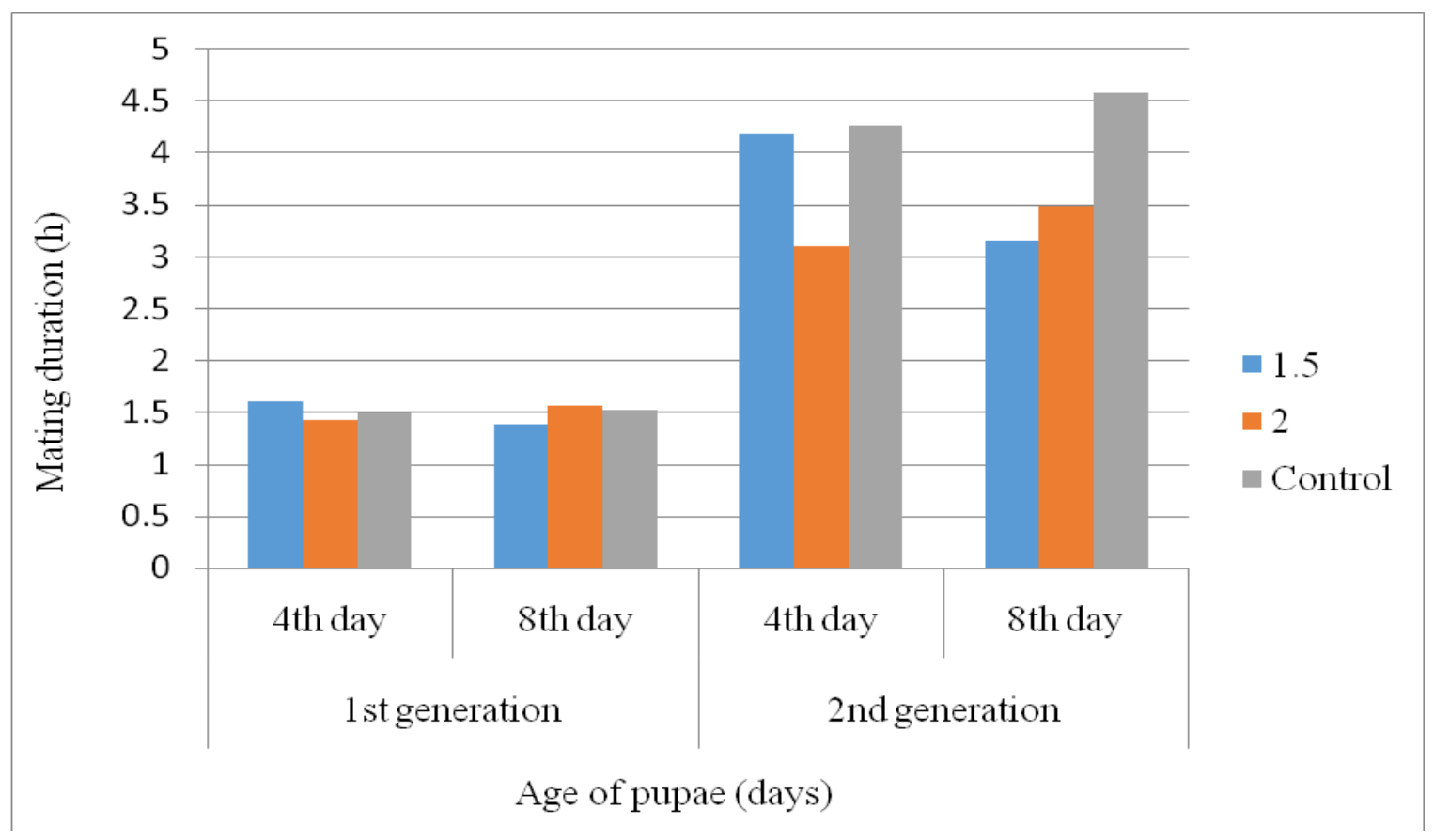


Fig.3 Ovipositional duration (days) of normal female uzi flies mated with male uzi flies emerged from irradiated pupae (first and second generations

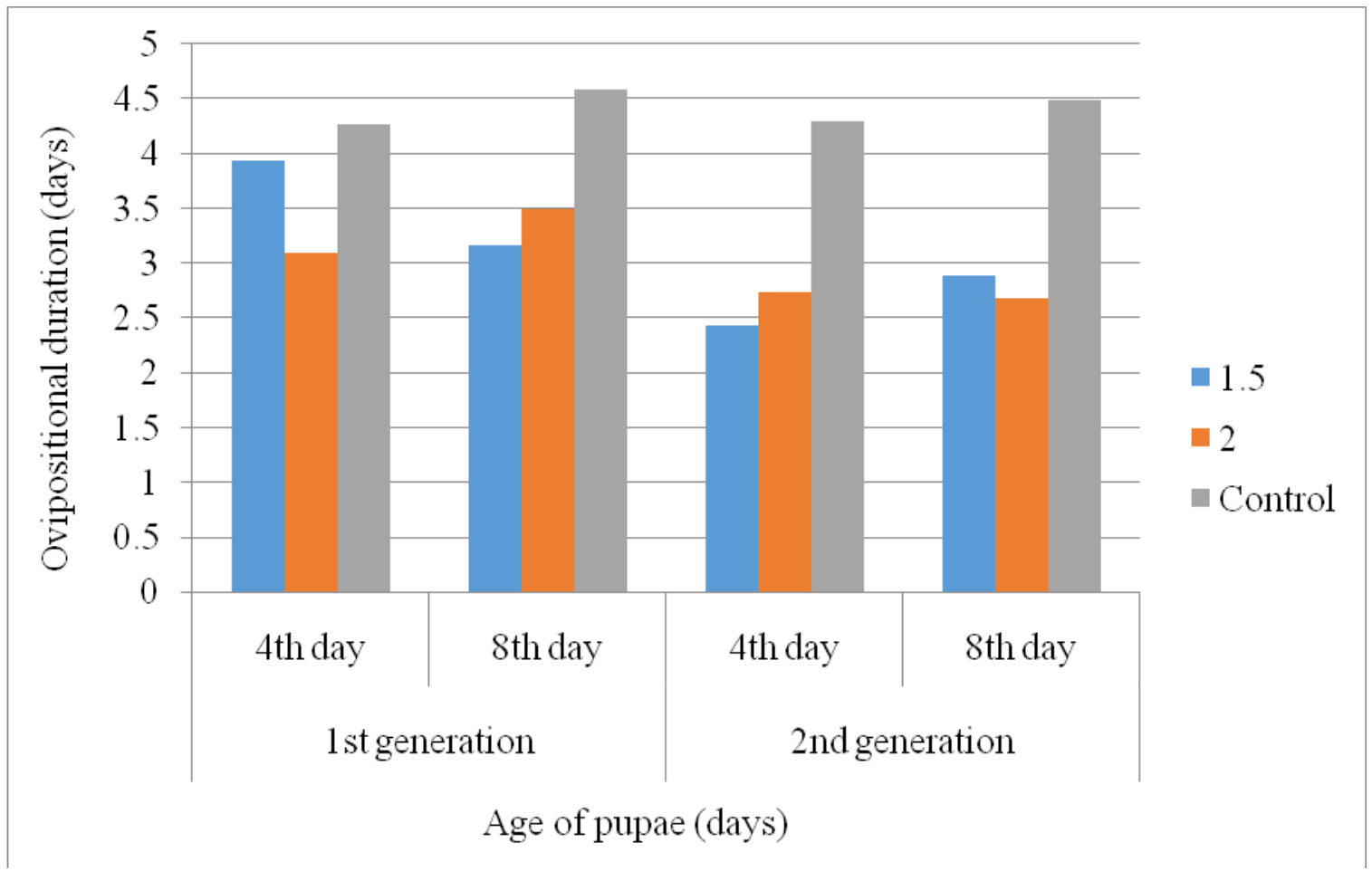

Ovipositional duration of normal female uzi flies mated with male uzi flies emerged from irradiated pupae

In the first generation, the ovipositional duration showed a significant difference between 1.5 and $2 \mathrm{kr}$ (3.94 days and 3.10 days) respectively when 4 day old pupae were irradiated and no significant difference between 1.5 and $2 \mathrm{kr}$ (3.16 days and 3.49 days) respectively when 8 day old pupae were irradiated. Whereas in the second generation, the ovipositional duration had no significant difference between the treatment means of 4and 8 old irradiated pupae (2.43 days and 2.74 days) respectively and there was no significant difference between the treatment means at 1.5 and $2 \mathrm{kr}$ (2.89 days and 2.68 days) respectively. The ovipositional duration was higher in control when compared to treated batches (Table 3 and Fig. 3). The statistical analysis revealed that the dose of radiation was significant and age of pupae was non-significant in the first generation whereas, the interaction effect is nonsignificant in the second generation. Similar results were recorded by Henneberry et al., (1963) when untreated males or males exposed to $8 \mathrm{kr}$ showed no difference in courtship time (27.5 and $28.8 \mathrm{~min}$ ) during their first or second matings respectively either on the same day of treatment or on the day of treatment. Males exposed to $16 \mathrm{kr}$ were slower $(53.0$ and $75.6 \mathrm{~min}$ ) to mate the first and second times on the day of treatment. However, 24 hours after treatment, males treated with $16 \mathrm{kr}$ had recovered and mated (30.7 and $32.3 \mathrm{~min}$ ) as readily as untreated males.

In conclusion, both the radiation doses (1.5 and $2 \mathrm{kr}$ ) induced sterility when male pupae were irradiated, but there is a difference between the age of pupae. Younger pupae are 
more susceptible to irradiation compared to older pupae. As the age of pupae advanced there was an increase in the resistance of the uzi flies to gamma radiation treatment. Gamma irradiation induces sterility not only in the first generation but the radiation effects have been carried over to the next generation.

\section{References}

Frank Eischen, A., Alford Dietz. and John Brower, H., 1984, Effect of aging on the mating competitiveness of irradiated male greater wax moths (Lepidoptera: Pyralidae). Journal of Economic Entomology, 77: 1534 - 1536.

Henneberry, T. J. and McGovern, W. L., 1963, Effects of gamma radiation on mating competitiveness and behavior of Drosophila melanogaster males. Journal of Economic Entomology, 56 (6): 739-741.
John, H. and Brower, 1976, Dose fractionation: effects on longevity, mating capacity, and sterility of the irradiated males of the Indian meal moth, Plodia interpunctella (Lepidoptera: Phycitidae). The Canadian Entomologist, 108: 823-826.

Knipling E.F., 1955, Possibilities of insect control or eradication through the use of sexually sterile males. Journal of Economic Entomology, 48: 459-462.

Knipling, E.F., 1959, Sterile male method of population control. Science, 130: 902904.

Narayanaswamy, K. C. and Devaiah, M. C., 1998, Silkworm uji fly. Zen Publishers, Bangalore, p. 232.

Vasudha, K., 2014, Induction of male sterility in silkworm uzi fly, Exorista bombycis (Louis) - A parasitoid of silkworm, Bombyx mori L. Ph.D. Thesis, UAS, Bangalore, p.83-86.

\section{How to cite this article:}

Ashwini, G. and Fatima Sadatulla. 2019. Pre-mating, Mating and Ovipositional duration of Gamma Irratated Uzi Fly, a Parasitoid of Mulberry Silkworm Bombyx mori L.. Int.J.Curr.Microbiol.App.Sci. 8(03): 2490-2497. doi: https://doi.org/10.20546/ijcmas.2019.803.295 